MIDAS

Museus e estudos interdisciplinares

$10 \mid 2019$

Varia

\title{
François Mairesse (ed.) - Nouvelles Tendances de la Muséologie
}

\section{Graça Filipe}

\section{(2) OpenEdition}

\section{Journals}

\section{Edição electrónica}

URL: http://journals.openedition.org/midas/1526

DOI: $10.4000 /$ midas. 1526

ISSN: 2182-9543

\section{Editora:}

Alice Semedo, Paulo Simões Rodrigues, Pedro Casaleiro, Raquel Henriques da Silva, Ana Carvalho

\section{Refêrencia eletrónica}

Graça Filipe, «François Mairesse (ed.) - Nouvelles Tendances de la Muséologie », MIDAS [Online], 10। 2019, posto online no dia 31 maio 2019, consultado no dia 23 setembro 2020. URL : http:// journals.openedition.org/midas/1526; DOI : https://doi.org/10.4000/midas.1526

Este documento foi criado de forma automática no dia 23 setembro 2020.

\section{(c) (i) (2) (2)}

Midas is licensed under a Creative Commons Attribution-NonCommercial-ShareAlike 3.0 International License 


\title{
François Mairesse (ed.) - Nouvelles Tendances de la Muséologie
}

\author{
Graça Filipe
}

\section{REFERÊNCIA}

Mairesse, François, ed. 2016. Nouvelles Tendances de la Muséologie. Paris: La

Documentation française. 246 páginas, ISBN: 978-2-11-010308-6.

1 Este livro debruça-se sobre a museologia e as suas novas tendências analisadas principalmente através das transformações que ocorrem actualmente no mundo dos museus e no campo museal, não só na Europa mas noutros continentes, como em África ou na Ásia. ${ }^{1}$ Sem que se dissociem passado, presente e futuro, os museus, a par de processos e instituições patrimoniais, são objecto de reflexão por vários autores, sob contextos contemporâneos e visões várias de evoluções futuras das sociedades.

2 A publicação, de 2016, sob a direcção de François Mairesse, sequencia o 37. simpósio sobre as novas tendências da museologia do ICOFOM (Comité Internacional para a Museologia) do ICOM (Conselho Internacional de Museus), co-organizado com entidades académicas e com museus franceses, realizado em 2014 em Paris. François Mairesse é professor universitário, autor de numerosos livros de referência na museologia contemporânea e actual presidente do referido comité.

Lembremos que um dos objectivos por que este comité do ICOM foi fundado em 1977 foi estabelecer a museologia como disciplina científica universitária.

4 O livro em recensão reúne ensaios de vários especialistas da Europa e da América, sobre a maioria dos aspectos considerados susceptíveis de transformar o campo museal nos próximos anos. A maioria dos ensaios resulta de investigação conduzida no meio académico, cingindo-se a sua proveniência à Europa e à América, embora alguns tratem de importantes transformações de museus noutros continentes: em África e na Ásia.

Começando pelos autores europeus, de França, para além do próprio François Mairesse, participam no livro Daniel Jacobi, Serge Chaumier, Yves Girault (sobre museus 
africanos), Bernard Deloche, Brigitte Juanals e Jean-Luc Minel, Vincent Puig e MarieSylvie Poli. De Espanha, contribuem Jesús Pedro Lorente e Xavier Roigé. Passando ao continente americano, do Brasil, um artigo de Teresa Scheiner integra o livro. E do Canadá colaboram Bernard Schiele (debruçando-se sobre os museus da China) e Yves Bergeron.

6 Dos vários artigos transparece o carácter polimorfo da museologia, consoante os autores e as disciplinas a que o seu campo de investigação está associado. Daniel Jacobi, por exemplo, designa-a como um "domínio polissémico" (p. 27).

No prefácio do livro, a cargo da directora-geral do ICOM, Anne-Catherine RobertHauglustaine, esta evoca quer a popularidade do museu enquanto entidade cultural, quer o actual estado de mutação e de novos desafios do universo museal, a par de questões sobre o seu futuro e de uma necessária reflexão, incluindo de ordem ética.

8 Segue-se uma introdução de François Mairesse, que nos oferece uma excelente sistematização dos 12 ensaios ou artigos que integram o livro, interrelacionando as grandes linhas de transformação abordadas pelos seus autores. Ajuda a contextualizar várias correntes teóricas e de investigação, identifica campos geográficos e desenho de tendências para o futuro dos museus e aponta a importância das mudanças geracionais que neles também se vivem. A introdução de François Mairesse ajuda-nos ainda a uma leitura crítica de vários artigos reunidos no livro, pois convoca-nos pontualmente para outros autores e referências bibliográficas incontornáveis sobre os temas em análise. Nunca deixando de ter presentes as marcas e repercussões ocorridas a partir da crise económica de 2007, questiona qual será o quadro de evolução dos museus nos próximos dez ou 15 anos, segundo os estudos de prospectiva com que o próprio sector se interroga sobre o futuro. Evocando o trabalho do Center for the Future of Museums (American Alliance of Museums), insiste no reconhecimento de que a demografia, a educação e a evolução das tecnologias influenciam os museus e a maneira de fazer investigação e de a difundir (p. 25).

Identifica uma mudança geracional em curso no mundo da museologia e uma renovação de referências que se operacionaliza na educação/formação de novos museólogos, os quais desenvolvem novos eixos de investigação (transformações no universo académico; novas soluções de educação transnacionais e novos modos de aprendizagem com recurso a tecnologias de informação e comunicação, com relevância também para as questões linguísticas). Sublinha a indubitável e contínua transformação do campo museal e da museologia, por vezes de modo superficial, mas também de maneira estrutural (p. 26).

Em causa está o problema do reconhecimento da museologia, quer ligado a métodos e processos de investigação, quer sobretudo enquanto rede complexa, pela relação com os seus actores (laboratórios ou centros e investigadores), instrumentos de divulgação e de (re) conhecimento científico, laços estabelecidos com organismos estatais, com a indústria ou com o grande público. Mas no próprio livro se reconhece que não existe uma visão detalhada e de conjunto dessa rede espalhada pelo mundo (p. 15). Assim como se reconhece que, apesar dos museus poderem ser considerados um fenómeno bastante popular à escala mundial (p. 11; 15), o campo da museologia é muito restrito, nomeadamente se comparado com outros campos disciplinares mais clássicos e não dispõe ainda de uma linguagem, de instrumentos e de conceitos operativos partilhados ou unanimemente aceites, nem mesmo no campo museal (p. 15). É neste contexto que têm particular realce algumas correntes, ora funcionando como centros de formação, 
associando a museologia a outras disciplinas (como a Escola de Avignon em que Jean Davallon tem um papel fundador), ora como corpus de experiências concretas, ou investigação em contexto de aplicação, esbatendo limites entre investigação e prática, como as correntes designadas de nova museologia, de sociomuseologia e de museologia crítica, entre outros termos e designações em que transparece a heterogeneidade do campo museal e a vontade de renovar o campo de investigação (p. 17).

11 Segundo Daniel Jacobi, a originalidade da Escola de Avignon ao participar na criação e no desenvolvimento da museologia no panorama universitário francófono foi combinar métodos de inspiração semiótica (análise formal das exposições ou das mediações) com outros mais próximos da psicologia e da sociologia (aculturação e públicos) (p. 28). o mesmo autor reconhece três museologias: (1) a noção básica de uma área de saber sobre a vida dos museus e as suas actividades mais conhecidas do público; (2) a prática reflectida de um profissional, que formaliza a sua reflexão para a poder comunicar e transmitir a outros, visando melhorar a eficácia das próprias práticas profissionais; (3) um domínio de investigação, com produção de novos conhecimentos sobre a história e as colecções dos museus, sobre as instituições museográficas, as exposições e os seus públicos. É sob esta terceira acepção de museologia que Daniel Jacobi distingue três fases principais na evolução dos museus: (i) o museu moderno herdado do século XIX; (ii) o de fim do século XX, vivendo ao ritmo da exposição; (iii) a fase da aceleração e da preeminência do evento, da aposta no virtual, em dependência do imediato e a que está associada a fidelização de visitantes e o incremento da sua frequentação, como preocupação comum a outros ditos equipamentos culturais, mais do que o alargamento e o aumento de visitantes (p. 35). Como todas as hipóteses e teorizações uniformizadoras, creio que estas também necessitam de ser relativizadas no momento da aplicação, caso a caso, tendo em conta a formulação instável e mutável dos museus.

Neste livro surge ainda uma outra questão muito pertinente, aqui contundentemente equacionada: a dos laços do património com os museus e com a museologia, apresentando Serge Chaumier uma visão de ruptura, de separação dos dois domínios: « Pourquoi la Muséologie ne Devra Plus Être une Composante du Patrimoine». Este é um artigo que destaco porque nos remete para uma importante reflexão filosófica sobre o paradigma patrimonial e uma inerente visão do mundo e sobre o papel que os museus podem desempenhar. Explorando fundamentalmente a evolução contemporânea das instituições museais em França, Serge Chaumier analisa a sua dicotomia com o património, por razões de ordem política, de ordem histórica, de ordem sociológica e de ordem epistemológica.

Já Teresa Scheiner («Réfléchir sur le Champ Museal: Signification et Impact Théorique de la Museólogie») defende que para manter a sua identidade como área de conhecimento fora da sociologia, à museologia devem consignar-se tanto o museu como o património enquanto seus objectos específicos (p. 50). A autora vê a museologia como instância privilegiada do campo cultural e como instrumento de apreensão do património e de valorização social, considerando-a articulada com os campos da filosofia, da arte e da comunicação, que formariam a natureza do fenómeno de conhecimento e de percepção do real, a que se chama museu. Potencialmente reinventável e redimensionável, em diferentes pontos do nosso planeta e sob novas formas de praticar a museologia, mas provavelmente não será um fenómeno cultural permanente (p. 53).

Num quadro geográfico de análise mais vasto e atento a diferentes lógicas de funcionamento dos museus nos diversos continentes, Bernard Schiele aborda o caso da 
China e a transformação do parque museal chinês a partir dos anos 2000, considerando a sua extensão como facto notável no mundo contemporâneo dos museus e revelador da evolução da museologia.

Por sua vez, Yves Girault traça a história do fenómeno museal em África e analisa detalhadamente as inovadoras formas de trabalho sobre o património, através do sistema de bancos culturais organizados nos últimos anos.

Analisando algumas formas e meios por que vem ocorrendo a investida do digital no museu, e as consequentes mudanças de práticas e de valores, Bernard Deloche, no artigo intitulado "L'irruption du Numérique au Musée: de la Muséologia à la Noologie», aponta a "noologia" como uma das perspectivas de evolução da museologia, que considera provavelmente incapaz de pensar o espírito global do ciberespaço ("noosfera") e de o explorar e cartografar, a fim de tornar inteligível a desordem de que é composto.

Debruçando-se sobre as repercussões da era do digital nos museus, Brigitte Juanals e Jean-Luc Minel - «Stratégies de Communication et Dispositifs de Médiation à l'ère Numérique: Vers des 'Musées Ouverts'?» - analisam sistematicamente as estratégias de comunicação e os dispositivos que vêm sendo introduzidos. Com base numa reflexão prospectiva, consideram que uma parte dos desafios presentes e futuros - incluindo os tipos de investigação que os museus poderão levar a cabo sobre as suas colecções - passa pela exigência de interoperabilidade de dados e normas internacionais comuns, para a criação de um novo espaço cultural partilhado.

18 Também o artigo de Vincent Puig - "Écrire le Patrimoine àl'âge des Datas - Enjeu de l'indexation Contributive» - recai no plano da tecnologia digital, mais especificamente sobre as relações entre os objectos digitalizados e os públicos, evidenciando as linhas de trabalho que os museus têm de desenvolver no tratamento da informação que produzem, assim como a importância das acções colaborativas de indexação de dados e as novas relações de poder e de contrapoder geradas pelas novas formas e mecanismos de disponibilização e acesso ao conhecimento na Internet.

ente diferente é a abordagem museológica de Marie Sylvie Poli - «Pour une Poétique du Musée et de la Muséologie Aujord-hui» - em que se serve da ficção de alguns autores contemporâneos para analisar o lugar que atribuem aos museus e inferir que apesar de vistos em geral como instituição elitista, nem por isso deixam de ser crescentemente reconhecidos pela sociedade.

20 Yves Bergeron encerra o livro com um ensaio que creio imprescindível e de que se tira o benefício de uma visão de síntese: «Musées et Muséologie: Entre Cryogénisation, Ruptures et Transformations». Realça o interesse em abordar as grandes tendências da museologia e como estas recaem na análise das rupturas, das transformações e das mutações de uma instituição que atravessa o tempo e se lhe adapta e que sob esta perspectiva o estudo dos museus e da museologia permite reflectir sobre os grandes temas e desafios societais (p. 246).

21 Finalmente, creio relevante referir que este livro é dedicado à memória de Zbynëk Stránský (1926-2016). O ICOFOM revisitou a importância deste pensador (por alguns considerado o "pai da museologia científica") num encontro em 2015 e numa edição em 2017 - Anais do III Ciclo de Debates da Escola de Museologia da UNIRIO, Paris ICOFOM em que foram discutidos os fundamentos do campo museológico nas teorias 
contemporâneas e debatido o seu objecto de estudo. E é deste outro livro que, concluindo, citamos:

[...] desde que um certo número de pesquisadores decidam juntos trabalhar em uma mesma direcção e produzir uma pesquisa suficientemente apreciada, a Museologia poderia encontrar facilmente o seu lugar no nível académico. (Mairesse 2017, 90)

\section{BIBLIOGRAFIA}

Mairesse, François, 2017. “Zbyněk Stránsk'e a Bibliologia.” In Stránský: Uma Ponte Brno-Brasil. Anais do III Ciclo de Debates da Escola de Museologia da UNIRIO. Stránský: A Bridge Brno-Brazil. Annals of the III Cycle of Debats of the School of Museology of UNIRIO, editado por Bruno Brulon Soares, e Anaildo Bernardo Baraçal, 87-100. Paris: ICOFOM.

\section{NOTAS}

1. A autora escreve de acordo com a antiga ortografia.

\section{AUTORES}

\section{GRAÇA FILIPE}

Instituto de História Contemporânea, Faculdade de Ciências Sociais e Humanas da Universidade Nova de Lisboa, Portugal, gracafilipe@mail.telepac.pt 